\title{
PSYCHOLOGICA
}

\section{Caracterização de alunos repetentes: um estudo na região de Coimbra}

Autor(es): $\quad$ Rebelo, José A. S.; Fonseca, António C.

Publicado por: Imprensa da Universidade de Coimbra

URL

persistente:

URI:http://hdl.handle.net/10316.2/5473

DOI: $\quad$ DOI:http://dx.doi.org/10.14195/1647-8606_51_12

Accessed : $\quad$ 26-Apr-2023 12:32:06

A navegação consulta e descarregamento dos títulos inseridos nas Bibliotecas Digitais UC Digitalis, UC Pombalina e UC Impactum, pressupõem a aceitação plena e sem reservas dos Termos e Condições de Uso destas Bibliotecas Digitais, disponíveis em https://digitalis.uc.pt/pt-pt/termos.

Conforme exposto nos referidos Termos e Condições de Uso, o descarregamento de títulos de acesso restrito requer uma licença válida de autorização devendo o utilizador aceder ao(s) documento(s) a partir de um endereço de IP da instituição detentora da supramencionada licença.

Ao utilizador é apenas permitido o descarregamento para uso pessoal, pelo que o emprego do(s) título(s) descarregado(s) para outro fim, designadamente comercial, carece de autorização do respetivo autor ou editor da obra.

Na medida em que todas as obras da UC Digitalis se encontram protegidas pelo Código do Direito de Autor e Direitos Conexos e demais legislação aplicável, toda a cópia, parcial ou total, deste documento, nos casos em que é legalmente admitida, deverá conter ou fazer-se acompanhar por este aviso. 
NÚMERO 51

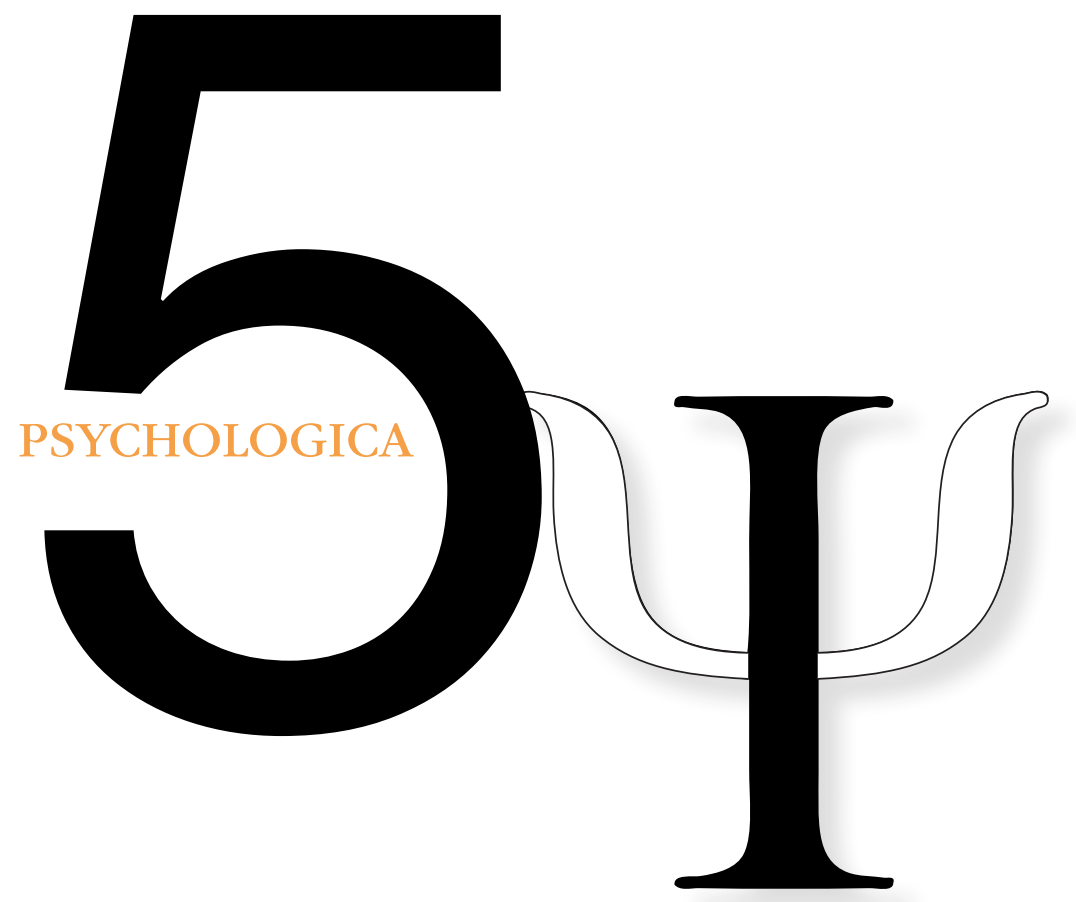

IMPRENSA DA UNIVERSIDADE DE COIMBRA

FACULDADE DE PSICOLOGIA E DE CIÊNCIAS DA EDUCAÇÃO DA UNIVERSIDADE DE COIMBRA 


\title{
Caracterização de alunos repetentes: Um estudo na região de Coimbra
}

\author{
José A. S. Rebelo' \& António C. Fonseca²
}

O presente trabalho utiliza dados de um estudo longitudinal, realizado no conceIho de Coimbra, para mostrar algumas características de alunos repetentes, desde o ensino básico ao secundário. O estudo começou em 1992/93 e tem vindo a ser continuado. Em diversos momentos, têm sido avaliados 445 alunos que, nesse ano, se encontravam no $2^{\circ}$ ano e 448 que, também nesse ano, frequentavam o $4^{\circ}$ ano de escolaridade. Sintetizamos, a seguir, os resultados conseguidos.

A retenção escolar, no sistema português de ensino, começa cedo e a maioria dos alunos não consegue acabar o ensino secundário sem alguma vez ter sido retido. De entre os repetentes, a maioria é constituída por rapazes. Nos primeiros anos de escolaridade, a retenção parece estar ligada a dificuldades na leitura e na escrita. Os repetentes precoces são de todos os repetentes os que mais desvantagens manifestam ao longo do percurso escolar, onde, geralmente, têm mais que uma repetência. Os pais dos repetentes têm níveis de escolaridade inferiores aos dos não repetentes e parecem mais ausentes do seu núcleo familiar. Muitos dos repetentes abandonam a escola sem obterem diploma.

PALAVRAS-CHAVE: repetência escolar; insucesso escolar; alunos repetentes; estudo de caracterização.

\section{Introdução}

Reter alunos no mesmo ano escolar ou deixá-los passar sem terem adquirido suficientemente os conhecimentos requeridos para o ano de escolaridade que frequentam é uma questão que, tanto em Portugal como no estrangeiro, preocupa e põe em confronto profissionais da educação, os pais ou encarregados de educação, as suas associações e até mesmo os políticos. É um assunto sobre que não há consenso e em que, geralmente, duas posições se extremam: os que são a favor da transição de ano por considerarem a retenção uma medida educativa

\footnotetext{
1 Linha de investigação $n^{\circ} 3$ - Human Development and Risk Behaviors - do Centro de Psicopedagogia, Universidade de Coimbra. jsrebelo@fpce.uc.pt.

2 Linha de investigação $n^{\circ} 3$ - Human Development and Risk Behaviors - do Centro de Psicopedagogia, Universidade de Coimbra. acfonseca@fpce.uc.pt.
} 
inútil; os que defendem um maior rigor na avaliação e exigem, por isso, que se acabe com o facilitismo de deixar passar os alunos sem saberem.

O debate e esta controvérsia existem desde há muito, mas é sobretudo nos últimos anos que um número mais alargado de cidadãos vem despertando interesse por este assunto. Segundo Jimerson e colaboradores (2006), durante a última década, nos E.U.A., talvez se não encontre outro tópico onde tenha havido tão grande divisão e discordância entre investigadores, educadores e o público em geral. E isto apesar da grande maioria da investigação ter vindo a mostrar, já desde há anos, que a retenção produz efeitos negativos.

No entanto, a retenção dos alunos continua a ser praticada e é, no sistema de ensino dos diversos países, uma das manifestações mais evidentes do insucesso escolar, conceito este muito variável de país para país, mesmo na Comunidade Europeia. Nuns países, por exemplo a Dinamarca, não se pratica a retenção ao longo dos 9 anos de ensino básico obrigatório. Noutros locais, como a Inglaterra, o País de Gales e a Irlanda, reconhece-se que no ensino há insucesso, quando os alunos têm desempenho abaixo das suas potencialidades, mas não se pratica a retenção. No sistema educativo escocês permite-se que certos alunos, com dificuldades de aprendizagem ou deficiências, se mantenham no sistema escolar após a idade do ensino obrigatório. A maioria dos países, porém, adopta as taxas de retenção e de abandono escolar como indicadores de insucesso escolar, as quais variam muito de país para país. Por exemplo, em Portugal, em 1991/92, a taxa de retenção atingia $23 \%$ no ensino primário ( $1^{\circ}$ ciclo) e $14.9 \%$ no final do $3^{\circ}$ ciclo do ensino básico, enquanto que, na Alemanha, em 1988, se registaram apenas $1.4 \%$ de retenções no ensino primário e $4 \%$ no secundário, sendo, na altura, neste mesmo país, $7.5 \%$ a taxa de abandono, no final do ensino secundário (Eurydice, 1995, pp. 46-48). Nos E.U.A, as taxas de retenção variam, actualmente, de 7 a 15\% (Jimerson et al., 2006).

As taxas de retenção e de abandono, além das políticas educativas de cada país, dependem dos mais variados factores, uns relacionados com os indivíduos (a sua situação social, económica, étnica ou o seu género), outros com a localização e tipo de escola (rural, suburbana, urbana, pública, privada), a região geográfica (litoral, interior), etc.. São tanto mais elevadas quanto maior for a combinação de factores considerados de risco (Jimerson et al., 2006).

Aos alunos retidos são, geralmente, apontadas pela investigação as características demográficas seguintes: em relação aos seus colegas, obtêm resultados fracos, sobretudo na leitura e em competências linguísticas, embora haja colegas seus, em situação semelhante, que passam de ano; têm maior probabilidade de ter mães de nível intelectual abaixo da média e com atitudes menos propícias à educação dos filhos; os seus pais empenham-se menos na escola do que os dos alunos 
não retidos; muitos alunos retidos têm problemas de comportamento e do foro sócio-emocional. Em países com população muito diversificada etnicamente, por exemplo os E.U.A., há grandes desproporções nas taxas de retenção segundo os grupos étnicos (p. ex., na população negra, a taxa de retenção é de $24 \%$, enquanto que na branca é de $8 \%$ e na asiática de 6\%) (Jimerson et al., 2006).

Analisando a taxa de repetição de ano por género, numerosos estudos sugerem que os rapazes têm cerca de duas vezes mais probabilidades de repetirem do que as raparigas, sendo esta probabilidade ainda maior em alunos pertencentes a minorias (cf. Jimerson et al., 2006).

Relativamente aos efeitos, a longo prazo, da retenção, os poucos estudos que examinaram a sua eficácia ao longo dos anos escolares, desde o $1^{\circ}$ ano do ensino básico até ao fim do secundário, mostram consistentemente que os alunos retidos têm maiores probabilidades de abandonar a escola sem obter diploma do que os seus colegas não retidos, incluindo nestes os que tiveram desempenhos escolares tão baixos como os dos repetentes. Por exemplo, os resultados duma revisão de estudos, feita por Jimerson, Anderson e Whipple (2002), mostram que os alunos retidos durante a escola elementar $\left(1^{\circ}-5^{\circ}\right.$ ano) têm entre uma a onze vezes mais probabilidades de abandonar o ensino secundário do que os não retidos e que, no seu conjunto, a repetição aumenta o risco de abandono, de 20 a 50\%.

Toda esta informação acabada de referir provém fundamentalmente de estudos realizados no estrangeiro. Será que os alunos repetentes portugueses têm características semelhantes às atrás indicadas? Tanto quanto é do nosso conhecimento, não há estudos científicos realizados sobre este tema em Portugal. Assim, pensamos que os dados que vamos a presentar são uma primeira tentativa para caracterizar os alunos repetentes das nossas escolas. O objectivo deste trabalho é, efectivamente, analisar e dar a conhecer algumas características dos alunos repetentes portugueses, constatadas através de um estudo longitudinal, realizado no concelho de Coimbra, que avaliou alunos em diversos momentos, durante o ensino básico até ao fim do secundário, tendo permitido, deste modo, recolher elementos para diferenciá-los, ao longo da sua escolaridade, quanto ao desempenho escolar e a eventuais características associadas a este.

Antes, porém, de apresentar o estudo, vamos expor algumas directrizes e informação que o Ministério da Educação disponibiliza, sobre a retenção e as suas respectivas taxas, em Portugal.

Por reprovação ou retenção escolar entende-se, vulgarmente, o "não passar de ano", ou, em linguagem corrente, "chumbar". A retenção dos alunos, no mesmo ano escolar que frequentam, é uma medida administrativa do sistema escolar de cada país, após avaliação dos resultados da aprendizagem dos programas esco- 
lares leccionados nesse ano curricular, em que esses resultados foram julgados insuficientes em relação aos padrões de avaliação estabelecidos.

No sistema de ensino português, o Ministério da Educação define assim a retenção escolar: "Situação escolar que, no final do a no lectivo, obriga o aluno a permanecer no mesmo ano de escolaridade, por razões de insucesso ou por ter ultrapassado o limite de faltas injustificadas" (GIASE, 2006, p. 18).

A razão para adoptar esta medida é o facto do aluno manifestar "um grande atraso em relação aos objectivos e capacidades definidas, a nível central e local, para esse ano ou ciclo" (Despacho Normativo n 98 - A/92, art.53) e a convicção de que, por meio dela, os alunos recuperarão os atrasos verificados e voltarão a estar ao nível da aprendizagem, considerada desde suficiente a óptima. Daí que a retenção seja vista como "assumindo carácter eminentemente pedagógico" (Despacho Normativo $\mathrm{n}^{\circ} 98-\mathrm{A} / 92$, art. 51).

A reprovação dos alunos é uma das decisões da avaliação, prevista no art. ${ }^{\circ} 14, n^{\circ} 2$, do Decreto-Lei $n^{\circ} 6$ de 2001: "Em situações de não realização das aprendizagens definidas no projecto curricular de turma para um ano terminal de ciclo que, fundamentalmente, comprometam o desenvolvimento das competências definidas para um ciclo de escolaridade, o professor titular de turma, no $1^{\circ}$ ciclo, ouvidos os competentes conselhos de docentes, ou o conselho de turma, no $2^{\circ}$ e $3^{\circ}$ ciclos, poderá determinar a retenção do aluno no mesmo ano de escolaridade, excepto no caso do $1^{\circ}$ ano de escolaridade" (Ministério da Educação, 2001).

Dos despachos ministeriais da última década e do capítulo $3^{\circ}$ do Decreto-Lei $n^{\circ}$ 6 de 2001, que trata da avaliação, facilmente se percebe que as orientações do Ministério da Educação vão no sentido de evitar que as escolas, na medida do possível, apliquem a medida da retenção. Porém, embora seja esta a intenção, a realidade é outra, a avaliar pelas estatísticas sobre as taxas de retenção que passamos a apresentar.

As taxas de reprovação mais recentes, no ensino básico, que o Ministério da Educação fornece, dizem respeito aos anos lectivos de 2005/06 e 2006/07 e são respectivamente as seguintes: $10.6 \%$ e $10.0 \%$. As percentagens variam de ciclo para ciclo e de ano para ano de escolaridade. Por exemplo, em 2005/06 e em $2006 / 07$, no $1^{\circ}$ ciclo, as mais altas ocorreram no $2^{\circ}$ ano, respectivamente $8.8 \%$ e $7.5 \%$; no $2^{\circ}$ ciclo, no $5^{\circ}$ ano, respectivamente $10.8 \%$ e $10.0 \%$ e, no $3^{\circ}$ ciclo, no $7^{\circ}$ ano, respectivamente $21.1 \%$ e $20.6 \%$. Num balanço que o Gabinete de Estatística e Planeamento da Educação (GEPE) faz dos 30 anos de estatísticas da educação em Portugal encontra-se a seguinte informação a respeito da retenção no ensino secundário: "É de salientar que a percentagem de alunos que não concluiu o $12^{\circ}$ ano, por reprovação ou desistência, se acentuou com a introdução de exames 
nacionais obrigatórios, no ano lectivo de 1995/96. A partir daí, a taxa de reprovações aumentou, estabilizando em valores próximos dos 50\%, em 2004" (GEPE, 2008, on-line).

Destes dados facilmente se poderá concluir que o número de alunos repetentes em Portugal é muito elevado, que varia de ciclo para ciclo e de ano para ano e que aumenta muito no final do ensino secundário, devido, sobretudo, aos exames nacionais.

Além desta informação geral sobre os alunos repetentes em Portugal, outros aspectos mais específicos é possivel considerar, através do estudo realizado na região de Coimbra, tais como: se a repetência ocorre nos primeiros anos ou mais tarde, se uma ou mais vezes, se varia segundo o género, o meio socioeconómico, a estrutura familiar e se tem alguma relação com o abandono escolar. É este estudo que passamos a analisar.

\section{Estudo realizado em Coimbra}

Em 1992/93, um grupo de investigadores da Faculdade de Psicologia e de Ciências da Educação da Universidade de Coimbra iniciou um estudo nas escolas do concelho de Coimbra e, desde esse tempo, tem recolhido muita informação, nomeadamente relativa ao percurso escolar dos alunos que fizeram parte da amostra e que, em diversos momentos da sua vida, foram novamente avaliados. Trata-se, portanto, de um estudo longitudinal.

A fundamentação, a metodologia e os resultados deste estudo, na sua primeira fase, foram apresentados em 1995 pela equipa de investigadores (Simões et al., 1995a; Simões et al., 1995b; Fonseca et al., 1995).

Foram feitas várias avaliações a esses alunos. Na primeira, em 1992/93, foram avaliados 445 alunos, que estavam no $2 .^{\circ}$ ano escolar (primeira coorte) e tinham 7-8 anos de idade, e 448 que frequentavam o $4 .^{\circ}$ ano (segunda coorte), com 10-11 anos de idade. $O$ número de rapazes e raparigas era semelhante. Os alunos da primeira coorte voltaram a ser avaliados mais três vezes (aos 11-12, 14-15 e 17-18 anos de idade), enquanto que os da segunda coorte apenas mais uma vez (aos 17-18 anos de idade). A última avaliação dos alunos, em ambas as coortes, ocorreu em período etário semelhante, isto é, quando tinham 17-18 anos de idade, altura em que estavam ou deveriam estar a acabar o ensino secundário.

Nas avaliações foram usados vários instrumentos com o objectivo de recolher, nas diversas fases do estudo, dados sobre diferentes áreas, tais como: resultados 
escolares, vinculação à escola, relacionamento com colegas, saúde mental, estatuto socioeconómico, família, tipo de comportamento, características individuais, abandono escolar, adaptação ao trabalho.

Apesar da abundância e do interesse de todos estes aspectos, que merecerão, 194 certamente, a atenção e análise noutros trabalhos, no presente estudo foram tidas apenas em conta as informações que pudessem caracterizar a população dos repetentes.

\section{Prevalências}

As prevalências da retenção escolar verificadas no grupo do $2^{\circ}$ e do $4^{\circ}$ ano vêm indicadas no Quadro 1, separadamente, para rapazes e raparigas. Os alunos foram distribuídos por 3 grupos: os repetentes de início precoce, os repetentes de início tardio e os não repetentes.

O critério para a formação do grupo "repetentes de início precoce" foi, para o grupo da primeira coorte ( $2^{\circ}$ ano), a "indicação pelos seus professores de que tinham repetido até ao $2^{\circ}$ ano de escolaridade", enquanto que para o de "início tardio" foi o de terem repetido, após esse ano, até à idade de 17-18 anos, quando se esperava que frequentassem o $12^{\circ}$ de escolaridade.

Para a segunda coorte ( $4^{\circ}$ ano), o critério adoptado para a formação do grupo "repetentes de início precoce" foi a "indicação pelos seus professores de que tinham repetido até ao $4^{\circ}$ ano de escolaridade", enquanto que o grupo de "repetentes de início tardio" compreende os que repetiram até aos 17-18 anos de idade.

Alertamos o leitor para, ao observar os Quadros, ter em consideração que, embora tenham sido estes os critérios para constituir os grupos, o número total de sujeitos e o de cada um dos grupos, nas variáveis a analisar, nem sempre é coincidente. É diferente porque, a respeito de alguns alunos, não foi possivel obter dados sobre o assunto em questão.

Quadro 1. Distribuição dos repetentes das duas coortes

\begin{tabular}{|c|c|c|c|c|c|c|}
\hline \multirow{2}{*}{ Primeira coorte ( $2^{\circ}$ ano) } & \multicolumn{2}{|c|}{ Rapazes } & \multicolumn{2}{|c|}{ Raparigas } & \multicolumn{2}{|c|}{ Total } \\
\hline & $\mathbf{N}$ & $\%$ & $\mathrm{n}$ & $\%$ & $\mathrm{n}$ & $\%$ \\
\hline Repetentes de início precoce & 72 & 30.0 & 28 & 13.7 & 100 & 22.5 \\
\hline Repetentes de início tardio & 87 & 36.3 & 75 & 36.6 & 162 & 36.4 \\
\hline Não repetentes & 81 & 33.8 & 102 & 49.8 & 183 & 41.1 \\
\hline Total & 240 & 100.0 & 205 & 100.0 & 445 & 100.0 \\
\hline
\end{tabular}




\begin{tabular}{|l|r|r|r|r|r|r|}
\hline \multirow{2}{*}{ Segunda coorte $\left(4^{\circ}\right.$ ano) } & \multicolumn{2}{|c|}{ Rapazes } & \multicolumn{2}{c|}{ Raparigas } & \multicolumn{2}{c|}{ Total } \\
\cline { 2 - 7 } & \multicolumn{1}{c|}{$\mathrm{n}$} & \multicolumn{1}{c|}{$\%$} & \multicolumn{1}{c|}{$\mathrm{n}$} & \multicolumn{1}{c|}{$\%$} & \multicolumn{1}{c|}{$\mathrm{n}$} & \multicolumn{1}{c|}{$\%$} \\
\hline Repetentes de início precoce & 79 & 33.9 & 61 & 28.4 & 140 & 31.3 \\
\hline Repetentes de início tardio & 82 & 35.2 & 54 & 25.1 & 136 & 30.4 \\
\hline Não repetentes & 72 & 30.9 & 100 & 46.5 & 172 & 38.4 \\
\hline Total & 233 & 100.0 & 215 & 100.0 & 448 & 100.0 \\
\hline
\end{tabular}

Como se verifica, a prevalência de repetentes do $2^{\circ}$ ano, de início precoce, é de $22.5 \%$, enquanto que a de início tardio, isto é, a dos que repetem a partir do $2^{\circ}$ ano até à idade de 17-18 anos, é de $36,4 \%$. A ocorrência de repetência precoce nas raparigas é menos de metade da dos rapazes, enquanto que a da tardia é semelhante em ambos os sexos.

Quando se observam as repetências no seu conjunto, do ensino básico ao secundário, a maioria dos rapazes inclui-se no grupo dos repetentes (66.3\%), enquanto que, neste grupo, apenas se encontra a metade das raparigas (50.2\%). No total os repetentes constituem a maioria (58.9\%).

O teste do qui-quadrado, tendo em conta as categorias de resultados dos alunos (repetentes de início precoce, repetentes de início tardio e não repetentes) e o género dos mesmos, conduziu a um valor que indica diferenças estatisticamente significativas entre as duas distribuições $\left[\chi^{2}(2)=20.03 ; p<0.01\right]$.

Quanto à segunda coorte ( $4^{\circ}$ ano), pode verificar-se no mesmo Quadro que, aos 17-18 anos de idade, a grande maioria $(61,7 \%)$ dos sujeitos pertence ao grupo dos repetentes, contando-se neste grupo um maior número de rapazes do que de raparigas. O número de repetentes de início precoce do sexo feminino é $5.5 \%$ inferior ao dos rapazes e, no de repetentes de início tardio, 10.1\% inferior.

Também nesta coorte, as diferenças entre os três grupos são estatisticamente significativas $\left[\chi^{2}(2)=11.93 ; p<0.01\right]$.

\section{Manifestação precoce de dificuldades de aprendizagem}

No primeiro tempo de avaliação (para a primeira coorte, aos 7-8 anos de idade; para a segunda, aos 10-11 anos), os alunos de ambas as coortes foram sinalizados pelos professores, com a indicação de se tinham ou não dificuldades de aprendizagem e da gravidade das mesmas. A informação recolhida junto dos professores permitiu obter a distribuição dos alunos que aparece no Quadro 2.

Dado não ter sido fornecida informação sobre todos os alunos, os totais gerais apresentados neste Quadro não coincidem com os do Quadro 1. 
Quadro 2. Distribuição dos repetentes em função das dificuldades de aprendizagem sinalizadas precocemente pelos professores

\begin{tabular}{|c|c|c|c|c|c|c|c|c|c|c|}
\hline \multirow{2}{*}{$\begin{array}{l}\text { Primeira coorte } \\
\qquad\left(2^{\circ} \mathrm{ano}\right)\end{array}$} & \multicolumn{2}{|c|}{$\begin{array}{c}\text { Sem } \\
\text { dificuldades }\end{array}$} & \multicolumn{2}{|c|}{$\begin{array}{c}\text { Dif. } \\
\text { Ligeiras }\end{array}$} & \multicolumn{2}{|c|}{$\begin{array}{c}\text { Dif. } \\
\text { Moderadas }\end{array}$} & \multicolumn{2}{|c|}{$\begin{array}{c}\text { Dif. } \\
\text { Graves }\end{array}$} & \multicolumn{2}{|c|}{ Total } \\
\hline & $\mathrm{N}$ & $\%$ & $n$ & $\%$ & $n$ & $\%$ & $n$ & $\%$ & $\mathrm{n}$ & $\%$ \\
\hline Repetentes de início precoce & 23 & 8.3 & 11 & 45.8 & 26 & 44.1 & 10 & 71.4 & 70 & 18.8 \\
\hline Repetentes de início tardio & 107 & 38.8 & 5 & 20.8 & 24 & 40.7 & 2 & 14.3 & 138 & 37.0 \\
\hline Não repetentes & 146 & 52.9 & 8 & 33.3 & 9 & 15.3 & 2 & 14.3 & 165 & 44.2 \\
\hline Total & 276 & 100.0 & 24 & 100.0 & 59 & 100.0 & 14 & 100.0 & 373 & 100.0 \\
\hline
\end{tabular}

\begin{tabular}{|c|c|c|c|c|c|c|c|c|c|c|}
\hline \multirow{2}{*}{$\begin{array}{l}\text { Segunda coorte } \\
\left(4^{\circ} \text { ano }\right)\end{array}$} & \multicolumn{2}{|c|}{$\begin{array}{c}\text { Sem dificul- } \\
\text { dades }\end{array}$} & \multicolumn{2}{|c|}{ Dif. Ligeiras } & \multicolumn{2}{|c|}{$\begin{array}{c}\text { Dif. } \\
\text { Moderadas }\end{array}$} & \multicolumn{2}{|c|}{$\begin{array}{c}\text { Dif. } \\
\text { Graves }\end{array}$} & \multicolumn{2}{|c|}{ Total } \\
\hline & $\mathrm{n}$ & $\%$ & $\mathrm{n}$ & $\%$ & $\mathrm{n}$ & $\%$ & $\mathrm{n}$ & $\%$ & $\mathrm{n}$ & $\%$ \\
\hline Repetentes de início precoce & 29 & 11.2 & 24 & 50.0 & 52 & 54.7 & 31 & 81.6 & 136 & 30.8 \\
\hline Repetentes de início tardio & 85 & 32.7 & 16 & 33.3 & 29 & 30.5 & 3 & 7.9 & 133 & 30.2 \\
\hline Não repetentes & 146 & 56.2 & 8 & 16.7 & 14 & 14.7 & 4 & 10.5 & 172 & 39.0 \\
\hline Total & 260 & 100.0 & 48 & 100.0 & 95 & 100.0 & 38 & 100.0 & 441 & 100.0 \\
\hline
\end{tabular}

Constata-se por este Quadro que a maioria dos repetentes de início precoce é, em ambas as coortes, sinalizada pelos seus professores como tendo dificuldades de aprendizagem de grau moderado a grave, enquanto que as dificuldades dos repetentes de início tardio são primordialmente conotadas de moderadas. Isto parece significar que os repetentes de início precoce dão mais nas vistas e são mais facilmente detectados, devido à gravidade das dificuldades de aprendizagem que manifestam. Curiosamente, há também alunos, de entre os repetentes precoces, embora em pequeno número e em ambas as coortes, cujas dificuldades de aprendizagem passam despercebidas aos professores. O mesmo sucede com alguns alunos que nunca repetiram, mas que foram sinalizados precocemente pelos seus professores como tendo dificuldades de aprendizagem, mesmo do tipo grave. Terão sido alunos para quem a escola ou os encarregados de educação encontraram modalidades de apoio eficazes?

\section{Repetência e desempenho académico precoce}

Na segunda avaliação, isto é, quando tinham 11-12 anos de idade, aos alunos da primeira coorte $\left(2^{\circ}\right.$ ano) foram administradas três provas académicas para avaliar o desempenho na leitura, na escrita e na matemática. A comparação dos grupos (repetentes precoces, tardios, não repetentes) nestas áreas revelou que os resultados mais baixos são os dos repetentes precoces, seguindo-se-lhes os dos tardios e, depois, os do grupo dos não repetentes. Análises da variância dos resultados obtidos mostraram que há diferenças estatisticamente significativas entre os grupos nas provas de leitura e de escrita, mas não na de matemática. 
Os valores obtidos foram os seguintes: para a leitura $[F(2,412)=37.24 ; p<0.001]$; para a escrita $[F(2,413)=25.03 ; p<0.001]$; para a matemática $[F(2,409)=0.23$; p>0.5]. Estes valores parecem indicar que, nos 4 primeiros anos de escolaridade, o sucesso escolar se fundamenta no desempenho em leitura e escrita, áreas do foro linguístico. Estes resultados estão em consonância com os estudos já citados na introdução, que a pontam para os repetentes dificuldades escolares sobretudo na leitura e lacunas em competências linguísticas.

\section{Repetentes e escolaridade dos pais}

Avaliámos, em ambas as coortes, a constituição dos grupos em função da escolaridade dos seus pais, procurando averiguar a existência de eventuais diferenças.

O Quadro 3 apresenta as médias do nível escolar dos pais dos alunos, distribuídos pelos três grupos, que foi avaliado numa escala de o (analfabeto) a 13 (com curso superior). Como se pode constatar, as médias indicam que o nível escolar de ambos os pais é mais baixo no grupo dos repetentes de início precoce, em relação aos dos repetentes de início tardio e aos não repetentes, sendo estes últimos os que têm pais com nivel escolar mais alto.

Quadro 3. Nivel escolar dos pais, em ambas as coortes e nos 3 grupos

\begin{tabular}{|c|c|c|c|c|c|c|}
\hline \multirow{3}{*}{$\begin{array}{l}\text { Primeira coorte } \\
\qquad\left(2^{\circ} \text { ano }\right)\end{array}$} & \multicolumn{6}{|c|}{ Nivel escolar } \\
\hline & \multicolumn{3}{|c|}{ Do pai } & \multicolumn{3}{|c|}{ Da mãe } \\
\hline & $\mathbf{N}$ & $M$ & DP & $\mathbf{N}$ & $M$ & DP \\
\hline Início precoce & 79 & 5.1 & 2.9 & 77 & 4.6 & 2.7 \\
\hline Início tardio & 119 & 6.4 & 2.9 & 120 & 5.9 & 2.7 \\
\hline Não-repetentes & 151 & 7.9 & 3.5 & 150 & 7.9 & 3.7 \\
\hline
\end{tabular}

\begin{tabular}{llllllll}
\hline \multirow{2}{*}{$\begin{array}{c}\text { Segunda coorte } \\
\left(4^{\circ} \text { ano }\right)\end{array}$} & \multicolumn{9}{c}{ Nivel escolar } \\
\cline { 2 - 8 } & & $\mathbf{N}$ & $\mathbf{M}$ & $\mathbf{D P}$ & $\mathbf{N}$ & $\mathbf{M}$ & DP \\
\hline Início precoce & 115 & 4.8 & 2.4 & 111 & 4.7 & 2.1 \\
\hline Início tardio & 110 & 6.4 & 3.1 & 107 & 6.3 & 3.0 \\
\hline Não-repetentes & 133 & 7.7 & 3.6 & 138 & 7.5 & 3.6 \\
\hline
\end{tabular}

As análises de variância utilizadas para comparar as médias revelaram que há diferenças significativas, quanto aos níveis de escolaridade dos progenitores (pai, mãe) a que pertencem os grupos, em ambas as coortes. Na primeira, os valores encontrados foram, para os pais $[F(2,346)=21.52 ; p<0.001]$ e para as mães $[F(2$, $344)=30.17 ; p<0.001]$; na segunda coorte $\left(4^{\circ}\right.$ ano), para os pais $[F(2,355)=25.53$; $p<0.001]$ e para as mães $[F(2,353)=25.31 ; p<0.001]$. 


\section{Repetentes e tipo de família}

O Quadro 4 apresenta a distribuição dos alunos das duas coortes, em função do tipo de família de que provêm, isto é: se têm pai e mãe e vivem com eles (família tradicional), se têm e vivem apenas com um destes (monoparental) ou se se encontram noutra situação (a viver com irmãos, avós, tios, primos, numa instituição, etc.).

Quadro 4. Distribuição dos repetentes em função do tipo de família, em ambas as coortes

\begin{tabular}{lrrrrrrrrr}
\hline \multirow{2}{*}{\begin{tabular}{c} 
Primeira coorte \\
\multicolumn{1}{c}{$\left(2^{\circ}\right.$ ano }
\end{tabular}} & \multicolumn{2}{c}{ Tradicional } & \multicolumn{2}{c}{$\begin{array}{c}\text { Monopa- } \\
\text { rental }\end{array}$} & \multicolumn{2}{c}{ Outra } & \multicolumn{2}{c}{ Total } \\
\cline { 2 - 11 } & \multicolumn{1}{c}{$\boldsymbol{n}$} & $\%$ & $\mathbf{n}$ & $\%$ & $\mathbf{n}$ & $\%$ & $\mathbf{n}$ & $\%$ \\
\hline Repetentes de início precoce & 73 & 22.1 & 12 & 23.1 & 15 & 53.6 & 100 & 24.4 \\
\hline Repetentes de início tardio & 129 & 39.1 & 25 & 48.1 & 8 & 28.6 & 162 & 39.5 \\
\hline Não repetentes & 128 & 38.8 & 15 & 28.8 & 5 & 17.9 & 148 & 36.1 \\
\hline Total & 330 & 100.0 & 52 & 100.0 & 28 & 100.0 & 410 & 100.0 \\
\hline
\end{tabular}

\begin{tabular}{|c|c|c|c|c|c|c|c|c|}
\hline \multirow{2}{*}{$\begin{array}{l}\text { Segunda coorte } \\
\left.\text { ( } 4^{\circ} \text { ano }\right)\end{array}$} & \multicolumn{2}{|c|}{ Tradicional } & \multicolumn{2}{|c|}{$\begin{array}{c}\text { Monopa- } \\
\text { rental }\end{array}$} & \multicolumn{2}{|c|}{ Outra } & \multicolumn{2}{|c|}{ Total } \\
\hline & $\mathrm{n}$ & $\%$ & $n$ & $\%$ & $\mathrm{n}$ & $\%$ & $\mathrm{n}$ & $\%$ \\
\hline Repetentes de início precoce & B5 & 30.7 & 13 & 37.1 & 37 & 42.0 & 135 & 33.8 \\
\hline Repetentes de início tardio & 91 & 32.9 & 9 & 25.7 & 34 & 38.6 & 134 & 33.5 \\
\hline Não repetentes & 101 & 36.5 & 13 & 37.1 & 17 & 19.3 & 131 & 32.8 \\
\hline Total & 277 & 100.0 & 52 & 100.0 & 88 & 100.0 & 400 & 100.0 \\
\hline
\end{tabular}

* N.B.: O total do $\mathrm{n}^{\circ}$ de sujeitos, nos grupos, não coincide com os de Quadros anteriores devido à falta de dados sobre alguns deles.

Por este Quadro, verificamos que, nos repetentes de início precoce, há uma percentagem maior de alunos, em relação aos restantes grupos, a viver num tipo de família que não é o tradicional (pais e irmãos), nem o monoparental - o que poderá significar que os repetentes precoces correrão, sob o ponto de vista da composição familiar, algum risco em termos de falta de oportunidades de vinculação e de supervisão, o que, por sua vez, se poderá reflectir em maior probabilidade de ocorrência de insucesso escolar. As três distribuições revelam-se estatisticamente diferentes em ambas as coortes, respectivamente, na $1^{\text {a }}$ coorte $\left[\chi^{2}(4)=16.34\right.$; $p<0.01]$ e na $2^{\mathrm{a}}\left[\chi^{2}(4)=10.27 ; p<0.05\right]$.

Analisámos também, em ambas as coortes, os grupos em função da eventual alteração da sua estrutura familiar durante todo o período escolar obrigatório. Os dados foram obtidos através da seguinte pergunta:"são as mesmas pessoas que viviam consigo há 9 anos?". Sendo a possibilidade de resposta o "sim" ou o "não, aplicado o teste do qui-quadrado, os valores encontrados foram os seguintes: para a $1^{\text {a }}$ coorte $\left[\chi^{2}(2)=6.0 ; p>0.05\right]$; para a $2^{a}\left[\chi^{2}(2)=2.5 ; p>0.05\right]$. Portanto, a análise da informação recolhida sobre este ponto não revelou diferenças significativas entre os grupos quanto ao número de elementos familiares com quem os alunos conviveram ou foram educados. 


\section{Resultados negativos nas disciplinas escolares}

O Quadro 5 mostra a média do número de negativas obtidas pelos 3 grupos nas disciplinas escolares, em diferentes períodos etários.

Como se verifica, aos 14-15 anos, os números médios de negativas dos repetentes de início precoce e de início tardio são superiores aos dos não-repetentes, sendo a diferença entre os três grupos estatisticamente significativa $[F(2,377)=68.58$; $p<0.001]$.

Aos 17-18 anos, a diferença do número médio de negativas dos 3 grupos de ambas as coortes é estatisticamente significativa, respectivamente para a primeira $[\mathrm{F}(2$, $354)=49.74 ; p<0.001]$ e para a segunda $[F(2,360)=5.28 ; p<0.001]$. Porém, nesta idade, o número médio de negativas é, em ambas as coortes, inferior ao da $1^{\mathrm{a}}$ coorte aos 14-15 anos de idade. Talvez isto se explique pelo facto de os alunos que, em idade mais precoce, tinham maior número de negativas, não se encontrarem em nenhuma instituição de ensino, aquando desta última avaliação, por terem abandonado a escola após a idade de frequência obrigatória de ensino, ou seja, após os dezasseis anos.

Quadro 5. Número médio e desvio-padrão de negativas nas disciplinas escolares nos 3 grupos

\begin{tabular}{|c|c|c|c|}
\hline \multicolumn{4}{|c|}{ Primeira coorte $\left(2^{\circ}\right.$ ano) } \\
\hline 14-15 anos & $\mathbf{N}$ & $M$ & DP \\
\hline Repetentes de início precoce & 69 & 3.2 & 2.1 \\
\hline Repetentes de início tardio & 151 & 3.4 & 2.2 \\
\hline Não repetentes & 160 & 1.0 & 1.5 \\
\hline 17-18 anos & $\mathrm{N}$ & $M$ & DP \\
\hline Repetentes de início precoce & 78 & 1.8 & 1.8 \\
\hline Repetentes de início tardio & 139 & 1.9 & 1.6 \\
\hline Não repetentes & 140 & 0.4 & 0.8 \\
\hline \multicolumn{4}{|c|}{ Segunda coorte ( $4^{\circ}$ ano) } \\
\hline $17-18$ anos & $\mathbf{N}$ & $M$ & DP \\
\hline Repetentes de início precoce & 107 & 2.2 & 1.9 \\
\hline Repetentes de início tardio & 123 & 2.7 & 8.9 \\
\hline Não repetentes & 133 & 0.7 & 1.0 \\
\hline
\end{tabular}

Os resultados negativos em disciplinas escolares da segunda coorte, expostos no Quadro 5, seguem o mesmo padrão de valores que os da primeira coorte, ou seja, as médias dos repetentes são mais altas do que as dos não repetentes, continuando a verificar-se diferenças estatísticas entre os três grupos $[F(2,360)$ $=5.28 ; p<0.001]$. 


\section{Número de repetências de anos escolares}

Pelo nosso estudo foi possível conhecer o número de reprovações que os alunos repetentes de início precoce e de início tardio tiveram ao longo da escolaridade. O Quadro 6 apresenta as médias de repetências dos alunos das duas coortes.

Quadro 6. Número médio e desvio-padrão de repetências dos grupos de ambas as coortes

\begin{tabular}{|c|c|c|c|}
\hline \multirow{2}{*}{ Primeira coorte ( $2^{\circ}$ ano) } & & & \\
\hline & $\mathbf{N}$ & M & DP \\
\hline Repetentes de início precoce & 96 & 2.2 & 1.0 \\
\hline Repetentes de início tardio & 161 & 1.7 & 0.8 \\
\hline Segunda coorte ( $4^{\circ}$ ano) & $\mathbf{N}$ & $M$ & DP \\
\hline Repetentes de início precoce & 140 & 2.5 & 1.1 \\
\hline Repetentes de início tardio & 136 & 1.7 & 0.9 \\
\hline
\end{tabular}

* N.B.: O total do $\mathrm{n}^{\circ}$ de sujeitos, nos grupos, não coincide com os de Quadros anteriores devido à falta de dados sobre alguns deles.

Em ambas as coortes, verifica-se que os repetentes de início precoce têm, ao longo da escolaridade, um maior número de repetências do que os de início tardio, sendo as diferenças entre os grupos (repetentes precoces versus tardios) estatisticamente significativas. Para a primeira coorte, os valores encontrados para a análise de variância foram $[F(1,255)=16.20$; $P<0.01]$ e, para a segunda $[F$ $(1,274)=43,12 ; p<0.01]$.

Por sua vez, o Quadro 7 fornece informação mais detalhada sobre as distribuições e frequência de repetências em cada um destes grupos e em ambas as coortes.

Quadro 7. Frequências das repetências nos grupos e nas coortes

\begin{tabular}{|c|c|c|c|c|c|}
\hline $\begin{array}{c}2^{\circ} \text { ano } \\
\left(1^{\mathrm{a}} \text { coorte }\right)\end{array}$ & $\mathrm{N}^{\circ}$ sujeitos & $\begin{array}{c}\text { Frequências } \\
\text { de repetências }\end{array}$ & $\begin{array}{c}4^{\circ} \text { ano } \\
\left(2^{a} \text { coorte }\right)\end{array}$ & $\mathbf{N}^{\circ}$ sujeitos & $\begin{array}{c}\text { Frequências } \\
\text { de repetências }\end{array}$ \\
\hline \multirow{6}{*}{ Início precoce } & 27 & 1 & \multirow{6}{*}{ Início precoce } & 24 & 1 \\
\hline & 35 & 2 & & 52 & 2 \\
\hline & 24 & 3 & & 39 & 3 \\
\hline & 8 & 4 & & 18 & 4 \\
\hline & 2 & 5 & & 5 & 5 \\
\hline & & & & 1 & 6 \\
\hline Total & 96 & & Total & 139 & \\
\hline \multirow{4}{*}{ Início tardio } & 77 & 1 & \multirow{4}{*}{ Início tardio } & 70 & 1 \\
\hline & 54 & 2 & & 43 & 2 \\
\hline & 26 & 3 & & 19 & 3 \\
\hline & 4 & 4 & & $\begin{array}{l}3 \\
1 \\
\end{array}$ & $\begin{array}{l}4 \\
6\end{array}$ \\
\hline Total & 161 & & Total & 136 & \\
\hline
\end{tabular}

* N.B.: O total do $n^{\circ}$ de sujeitos, nos grupos, não coincide com os de Quadros anteriores devido à falta de dados sobre alguns deles. 
Verifica-se que, nos repetentes de início precoce de ambas as coortes, um grande número de alunos repete, entre duas a três vezes, o mesmo ano escolar, havendo um pequeno grupo, embora mais pequeno, que reprova 4 a 6 vezes. Nos de início tardio, na primeira coorte ( $2^{\circ}$ ano), a maioria dos alunos ainda repete entre duas a três vezes, mas na segunda coorte ( $4^{\circ}$ ano) os que repetem entre 2 a 3 vezes já não são a maioria.

\section{Repetentes e abandono escolar}

Por fim, procurámos verificar a frequência com que o abandono escolar ocorre nos grupos. O Quadro 8 apresenta os resultados, nas duas coortes, com as respectivas percentagens.

Tomando como critério o abandono da escola antes de completar o $9^{\circ}$ ano de escolaridade, verificamos que em ambas as coortes os repetentes de início precoce abandonam em muito maior número a escola do que os alunos não repetentes. Na primeira coorte ( $2^{\circ}$ ano), os repetentes de início tardio, isto é, os que repetem após o $2^{\circ}$ ano de escolaridaride, são ainda em maior número a abandonar a escola do que os repetentes de início precoce. Na segunda coorte, o abandono escolar ocorre primordialmente nos que reprovam até ao $4^{\circ}$ ano de escolaridade inclusive, isto é, os repetentes de início precoce desta coorte.

Quadro 8. Abandono escolar (antes de completar $9^{\circ}$ ano): frequências e percentagens nas coortes e nos grupos

\begin{tabular}{|c|c|c|c|c|c|c|c|}
\hline $\begin{array}{l}2^{0} \text { ano } \\
\left(1^{\mathrm{a}} \text { coorte }\right)\end{array}$ & Abandono & $\begin{array}{c}\text { Não } \\
\text { Abandono }\end{array}$ & Total & $\begin{array}{l}4^{0} \text { ano } \\
\left(2^{\mathrm{a}} \text { coorte) }\right.\end{array}$ & Abandono & $\begin{array}{c}\text { Não } \\
\text { abandono }\end{array}$ & Total \\
\hline Início precoce & $\begin{array}{r}25 \\
39.1 \% \\
\end{array}$ & $\begin{array}{r}41 \\
51.9 \% \\
\end{array}$ & $\begin{array}{r}66 \\
46.2 \% \\
\end{array}$ & Início precoce & $\begin{array}{r}53 \\
84.1 \% \\
\end{array}$ & $\begin{array}{r}46 \\
63.0 \% \\
\end{array}$ & $\begin{array}{r}99 \\
72.8 \% \\
\end{array}$ \\
\hline Início tardio & $\begin{array}{r}35 \\
54.7 \% \\
\end{array}$ & $\begin{array}{r}20 \\
25.3 \% \\
\end{array}$ & $\begin{array}{r}55 \\
38.5 \% \\
\end{array}$ & Início tardio & $\begin{array}{r}6 \\
9.5 \% \\
\end{array}$ & $\begin{array}{r}23 \\
31.5 \% \\
\end{array}$ & $\begin{array}{r}29 \\
21.3 \% \\
\end{array}$ \\
\hline Não repetentes & $\begin{array}{r}4 \\
6.3 \% \\
\end{array}$ & $\begin{array}{r}18 \\
22.8 \% \\
\end{array}$ & $\begin{array}{r}22 \\
15.4 \% \\
\end{array}$ & Não repetentes & $\begin{array}{r}4 \\
6.3 \% \\
\end{array}$ & $\begin{array}{r}4 \\
5.5 \% \\
\end{array}$ & $\begin{array}{r}8 \\
5.9 \% \\
\end{array}$ \\
\hline Total Geral & $\begin{array}{r}64 \\
100 \% \\
\end{array}$ & $\begin{array}{r}79 \\
100 \% \\
\end{array}$ & $\begin{array}{r}143 \\
100 \% \\
\end{array}$ & Total Geral & $\begin{array}{r}63 \\
100 \% \\
\end{array}$ & $\begin{array}{r}73 \\
100 \% \\
\end{array}$ & $\begin{array}{r}136 \\
100 \% \\
\end{array}$ \\
\hline
\end{tabular}

* N.B.: O total do $n^{\circ}$ de sujeitos, nos grupos, não coincide com os de Quadros anteriores devido à falta de dados sobre alguns deles.

Dos que nunca repetiram, apenas uma percentagem relativamente pequena $(<7 \%)$ abandona a escola sem completar o $9^{\circ}$ ano escolar. Aplicado o teste do qui-quadrado para diferenciar os três grupos quanto ao abandono ou permanência no sistema escolar, após ter completado o $9^{\circ}$ ano de escolaridade, encontrámos diferenças significativas em ambas as coortes, com os seguintes valores: para a primeira $\left[\chi^{2}(2)=15.48 ; p<0.01\right]$; para a segunda $\left[\chi^{2}(2)=9.78 ; p<0.01\right]$. 


\section{Discussão}

Os resultados que foram apresentados ao longo deste trabalho mostram que, no sistema educativo português, a retenção no mesmo ano escolar afecta muitos alunos, sendo o número destes tanto maior quanto mais anos se mantiverem na escola. A constatação deste fenómeno já desde há muito tempo vem sendo feita, por estatísticas do Ministério da Educação, donde se conclui que ele continua a existir, teima em manter-se e resiste a mudanças. Com efeito, as percentagens do insucesso escolar do ano lectivo de 1995/96, comparadas com as de 2003/04, são praticamente iguais (GIASE, 2006).

Sendo assim, é grave que as escolas ainda não tenham tomado medidas para combater eficazmente o insucesso escolar que, além de se manifestar pelo abandono precoce da escola, se manifesta sob a forma da reprovação.

No início deste trabalho referimos que em 1991/92, ano anterior ao do início do estudo de Coimbra, a taxa de reprovação no ensino primário (fim do $1^{\circ}$ ciclo), foi, em Portugal, de $23 \%$. As últimas estatísticas sobre a retenção em Portugal, divulgadas pelo Ministério da Educação, dizem respeito ao ano lectivo de 2006/07 e, para o ensino obrigatório, ou seja, os 9 anos de escolaridade, são as seguintes: para o $1^{\circ}$ ciclo ( 4 anos de escolaridade) $4.5 \%$; para o $2^{\circ}$ ciclo ( $5^{\circ}$ e $6^{\circ}$ anos) $10.5 \%$; para o $3^{\circ}$ ciclo $\left(7^{\circ}, 8^{\circ}\right.$ e $9^{\circ}$ anos) $20.2 \%$. Mesmo sendo a percentagem de alunos repetentes precoces, actualmente, mais baixa do que era em 1992/93 (p. ex., no $2^{\circ}$ ano, em 2004/05, foi de $10.6 \%$, em 2005/06, 8.8\% e em 2006/07 foi de $7.5 \%$ (GEPE, 2008), verifica-se que, ao longo da escolaridade, ela vai aumentando, tornando-se muito elevada e indicadora de que o objectivo principal do sistema escolar, isto é, o sucesso escolar ou a aquisição de conhecimentos e competências indispensáveis à vida de todos os alunos, está longe de ser alcançado. Para tal, basta constatar que, pelos 17-18 anos de idade, isto é, pelo fim do secundário, os repetentes já formam a maioria!

Ora, recorrer a medidas de retenção, isto é, obrigar os alunos a repetir insistindo nos mesmos conteúdos no ano seguinte, deverá, segundo as directrizes para a avaliação, no sistema de ensino português, constituir uma medida de excepção e ter um "carácter eminentemente pedagógico". Assim, o seu principal objectivo deveriam ser as vantagens educativas para o aluno.

Em ambas as coortes do estudo de Coimbra, quer a do $2^{\circ}$, quer a do $4^{\circ}$ ano, a prevalência das repetências é alta e deveras surpreendente. Com efeito, cerca de $1 / 4$ dos alunos repetem o ano escolar precocemente, isto é, até ao $2^{\circ}$ ano e $1 / 3$ até ao $4^{\circ}$ ano. Além disso, ao longo da escolaridade, o número de repetentes vai engrossando, constituindo, no período que vai do ensino básico ao secundário, a maioria dos alunos das coortes por nós analisadas $\left(2^{\circ}\right.$ ano $=50.3 \% ; 4^{\circ}$ ano $=63.5 \%$ ). Os rapazes são os mais frequentemente retidos logo no $2^{\circ}$ ano, sendo neste período, 
em percentagem, mais do dobro das raparigas. No $4^{\circ}$ ano, essa diferença diminui bastante, mantendo-se, no entanto, ainda superior a $5 \%$, em relação às raparigas.

Dever-se-á esta diferença entre os sexos, em insucesso escolar precoce, a atrasos de maturidade escolar por parte dos rapazes, isto é, estarão os rapazes menos bem preparados ou desenvolvidos ao iniciar as aprendizagens escolares? Ou esta discrepância reflectirá simplesmente o mesmo padrão de diferenças que a investigação, em geral, costuma encontrar em estudos sobre dificuldades de aprendizagem e de formas de psicopatologia, onde, por vezes, a desproporção entre sexos é ainda maior?

Os professores têm um papel fundamental na detecção precoce das dificuldades de aprendizagem dos seus alunos e, como os dados deste estudo mostram, são capazes de o fazer, dando-se igualmente conta do tipo de gravidade que apresentam. Fazem-no sobretudo nas dificuldades de tipo grave, mais fáceis de detectar, que afectam sobretudo os repetentes de início precoce. Há, no entanto, um pequeno número de alunos com dificuldades de aprendizagem de tipo moderado a grave que passam despercebidos aos professores e para quem seria necessária uma detecção e observação precoces, de modo a, partindo destas, encontrar modos de os ajudar. Com efeito, a mera sinalização não basta! É preciso saber com precisão onde e em que matéria curricular específica encontram os alunos dificuldades. Ora, para esta tarefa nem sempre os professores estão preparados e dispõem de tempo e recursos para a executar, necessitando, frequentemente, de recorrer à ajuda de especialistas em dificuldades de aprendizagem, que, em geral, tiveram formação em Ciências da Educação ou em Psicologia Educacional.

O presente estudo, em consonância com investigações semelhantes, mostra que, a nivel de desempenho escolar, as dificuldades iniciais dos alunos repetentes se situam primordialmente na aprendizagem da leitura e da escrita, competências fundamentais no percurso escolar dos alunos, as quais, não sendo suficientemente adquiridas nos primeiros anos da escola elementar, influenciarão negativamente a escolarização e estarão, certamente, na base de novas repetências. Por isso, a detecção precoce de dificuldades de aprendizagem nestas áreas e a intervenção atempada nelas são, talvez, o modo mais eficaz de combater a repetência.

Sobre o ambiente cultural a que pertencem e de que dependem os alunos, constatou-se que, em ambas as coortes, o nivel de escolaridade dos seus pais os diferencia significativamente, quando divididos por repetentes precoces, tardios e não repetentes. Os precoces são os que têm pais com menos formação escolar, seguindo-se-lhes os repetentes tardios que, também neste ponto, se diferenciam significativamente dos que não repetiram. Influenciará esta situação o sucesso escolar futuro dos alunos? Se for este o caso, a escola deveria assumir um papel mais interveniente na ajuda a esses alunos e, eventualmente, estender a sua acção ao ambiente familiar deles. Aliás, muitas vezes, as escolas delegam nos 
pais ou encarregados de educação a ajuda suplementar (através, sobretudo, de trabalhos de casa) dos alunos. Não será esta uma forma de acentuar ainda mais as desvantagens de alguns alunos?

Segundo Miech e colaboradores (2001), o nivel de escolaridade dos pais é um bom preditor, quer do sucesso, quer do abandono escolar. Além disso, a relação entre insucesso escolar e meio sócio-económico desfavorecido vem já sendo enfatizada e comprovada pelas teorias sócio-culturais desde há muito tempo, procurando explicar aquele fenómeno (Boudon, 1973; Bernstein, 1975; Esperet, 1979; Litt, 1980). Os dados do estudo de Coimbra dão também indicações claras no mesmo sentido. Quanto ao tipo de família, este estudo regista, em ambas as cortes, uma percentagem significativamente maior de alunos com repetências precoces que não vivem em famílias consideradas normais (tradicionais ou monoparentais), possivelmente crianças e jovens institucionalizados ou a viver com familiares mais distantes. Terá isto significado relevante para os resultados escolares? Em alguns estudos, a família monoparental e outros tipos de família são apontados como factores de risco (Janosz \& Le Blanc, 1997). No entanto, isto não significa necessariamente que, em tipos diferentes da família tradicional, hoje cada vez mais comuns, se não possa encontrar factores de protecção suficientemente fortes que constituam um ambiente propício à educação e ao desenvolvimento geral da criança. Aliás, a análise que também fizemos a uma eventual ocorrência de mudança na estrutura familiar, para saber se as pessoas com quem os alunos viviam, nos primeiros anos de escolaridade, se mantiveram ou não as mesmas até aos 17-18 anos de idade, mostrou que tal facto não diferenciava significativamente os grupos, em ambas as coortes, o que poderá indicar que, ao longo dos anos, as crianças se vão adaptando à mudança, fenómeno normal das sociedades modernas.

O número de negativas em disciplinas escolares foi também analisado e, como era de esperar, os 3 grupos diferenciavam-se significativamente entre si. O insucesso escolar, uma vez iniciado, parece não ter retrocesso e reaparece ao longo da escolaridade. Esta tendência parece insolúvel num sistema educativo onde as alternativas ao currículo comum e igual para todos são escassas e pouco atractivas.

Quanto ao abandono da escola antes de completar o $9^{\circ}$ ano de escolaridade, isto é, até ao final da escolaridade obrigatória, verificamos que, em ambas as coortes, os repetentes, tanto de início precoce como os de início tardio, abandonam em muito maior número a escola do que os alunos não repetentes. Além disso, são os repetentes de início precoce que, relativamente aos outros grupos, abandonam mais frequentemente a escola sem obter o diploma do $9^{\circ}$ ano de escolaridade (cf. também Taborda Simões et al., 2008).

Outros estudos longitudinais constataram igualmente uma forte relação entre retenção e abandono escolar. Por exemplo, Alexander e colaboradores (2003) 
consideram ser o abandono o efeito mais negativo e praticamente o único da retenção escolar, enquanto que Jimerson e Ferguson (2007) apontam-Ihe variadissimas outras desvantagens, onde incluem o abandono escolar. Segundo estes autores, em conformidade com o seu estudo longitudinal mais recente, os alunos retidos tinham, de 5 a 9 vezes, maior probabilidade de abandonar os estudos do que os que sempre transitaram de ano, incluindo neste grupo os que passaram de ano com grandes atrasos.

A partir deste trabalho, que analisa e apresenta resultados do estudo longitudinal de Coimbra, respeitantes sobretudo a aspectos demográficos, que permitem caracterizar alunos portugueses repetentes, poderão tirar-se algumas conclusões. Em primeiro lugar, uma conclusão geral: os alunos com insucesso escolar, em especial quando este é precoce e sancionado pela medida administrativa da repetição do ano lectivo já frequentado, continuam, na sua grande maioria, a ter insucesso ao longo da escolaridade, evidenciado pela obtenção de negativas e por novas repetências. A população dos repetentes é, em Portugal, muito numerosa, mesmo actualmente, pois afecta, logo no primeiro ciclo, mais de um décimo da população escolar e, no final do ensino secundário, cerca de metade dos alunos. A percentagem de repetentes, logo nos primeiros anos de escolaridade, no estudo de Coimbra, é cerca do dobro da referida aos alunos actuais do primeiro ciclo, mas está em consonância com a existente no ano em que o estudo começou (1992/93). Este, porque acompanhou e avaliou os mesmos alunos até aos 17-18 anos, fornece elementos da sua trajectória escolar e dá a conhecer algumas das suas características. Em primeiro lugar, a maioria dos repetentes é, ao longo do percurso escolar, desde o básico ao fim do secundário, do sexo masculino, e a desproporção entre rapazes e raparigas é particularmente notória nos primeiros anos escolares, sobretudo até ao fim do $2^{\circ}$ ano, onde, no grupo de repetentes, os rapazes são mais do dobro das raparigas. Nos primeiros anos, a repetência parece estar particularmente ligada à dificuldade de automatização dos mecanismos da leitura e da escrita, isto é, à descodificação da linguagem escrita e codificação, em caracteres gráficos, da linguagem oral. Os repetentes têm pais com níveis de escolaridade mais baixos e vivem mais frequentemente em famílias sem a presença daqueles do que os seus colegas que nunca repetiram qualquer ano escolar. Finalmente, tal como outros estudos mostraram, uma das características dos repetentes, sobretudo dos precoces, é abandonarem a escola sem obterem diploma.

Tendo presentes estas conclusões, não será descabido afirmar que os repetentes, em especial os de início precoce, necessitam de identificação e de diagnóstico atempados e de uma intervenção adequada e rápida, dentro do sistema de ensino ou paralelamente a este, para que os seus problemas de aprendizagem se não agravem e sejam superados ou diminuídos rapidamente, de modo a não provocarem efeitos negativos no seu desenvolvimento geral e no percurso escolar, e 
não conduzirem ao abandono da escola sem a obtenção de diploma. Além disto, segundo a investigação, as repetências andam, desde cedo, associadas a um vasto leque de outros factores de risco, onde se incluem as desvantagens familiares, culturais, económicas e sociais, problemas emocionais e de comportamento, pelo que a intervenção não poderá apenas cingir-se ao ambiente escolar.

Embora não tenham sido incluídas muitas outras desvantagens que estudos neste domínio referem como associadas à retenção escolar, constatadas também pelo estudo longitudinal de Coimbra, os dados apresentados parecem suficientes para admitir que, sob o ponto de vista pedagógico, a medida administrativa de reter alunos, pensando ajudá-los, não tem fundamentação objectiva que confirme a sua eficácia. Pelo contrário, os efeitos são negativos, resultam em insucesso e abandono escolar que, em sociedades desenvolvidas e cada vez mais exigentes, do ponto de vista da adaptação à mudança e da aquisição de novos conhecimentos, são sinais e fonte de pobreza e de exclusão social.

Já há mais de 30 anos outros investigadores em educação defenderam que a retenção escolar não é justificável, é discriminatória, prejudicial e não serve para ajudar os alunos (Abidin et al., 1971). Com efeito, ela atinge sobretudo os alunos mais desfavorecidos, de minorias étnicas e de fracos recursos socioeconómicos, os quais, devido à dimensão da problemática que apresentam, necessitam, muitas vezes, de intervenção precoce e ajuda ao longo da escolaridade, para poderem superar ou diminuir as situações de desvantagem.

\section{Referências bibliográficas}

Abidin, R. R., Golladay, W. M., \& Howerton, A. L. (1971). Elementary school retention: An injustifiable, discriminatory, and noxious policy. Journal of School Psychology, 9, 410-414. Alexander, K.L., Entwisle, D. R. \& Dauber, S. L. (2003). On the success of failure. A reassessment on the effects of retention in the primary school grades. 2.nd ed. Cambridge: Cambridge University Press.

Bernstein, B. (1975). Langage et classes sociales, codes sociolinguistiques et contrôle social. Paris: Editions de Minuit.

Boudon, R. (1973). L'inégalité des chances. La mobilité sociale dans les societés industrielles. Paris: Ed. Armand Collin.

Esperet, E. (1979). Langage et origine sociale des élèves. Berne: Ed. Peter Lang.

Eurydice (Rede europeia para o combate ao insucesso escolar) (1995). A luta contra o insucesso escolar: Um desafio para a construção europeia. Lisboa: DEP/GEP (Ministério da Educação). 
Fonseca, A. C., Simões, A., Rebelo \& J. A. Ferreira, J. A. (1995). Comportamentos anti-sociais no ensino básico: As dimensões do problema. Revista Portuguesa de Pedagogia, 26 (3), 85-105.

GEPE (Gabinete de Estatística e Planeamenteo da Educação) (2008). Séries Cronológicas - 30 Anos de Estatísticas da Educação. Lisboa: Ministério da Educação. Consultado em Março de 2008, http://www.gepe.min-edu.pt/np3/14.html.

GIASE (Gabinete de Informação e Avaliação do Sistema Educativo) (2006). Estatísticas da Educação 04/05. Lisboa: Ministério da Educação.

Janosz, M. \& Le Blanc, M. (1997). Les décrocheurs potentiels au secondaire: Prévalence, facteurs de risque et dépistage. Prisme, 7 (2), 12-27.

Jimerson, S. (2004). Is grade retention educational malpractice? Empirical evidence from meta-analyses examining the efficacy of grade retention. In H. J. Walberg, A. J. Reynolds, M. C. Wang, \& J. B. Manning (Eds.). Can unlike students learn together? (pp. 1-96). Greenwich, C. T. : Information Age.

Jimerson, S. R., Anderson, G. E., \& Whipple, A. D. (2002). Winning the battle and losing the war: Examining the relation between grade retention and dropping out of high school. Psychology in the schools, 39, 441-457.

Jimerson, S. R. \& Ferguson, Ph. (2007). A longitudinal study of grade retention: Academic and behavioural outcomes of retained students. School Psychology Quarterly, 14 (3), 314-339.

Jimerson, S. R., Pletcher, S. M. W., Graydon, K., Schnurr, B. L., Nickerson, A. B., \& Kundert, D. K. (2006). Beyond grade retention and social promotion: Promoting the social and academic competence of students. Psychology in the Schools, 43 (1), 85-97.

Litt, J. L. (1980). Origine sociale et scolarité. Louvain-La-Neuve: Institut des Sciences Politiques et Sociales.

Miech, R., Essex, M. J. \& Goldsmith, H. H. (2001). Socioeconomic status and the adjustment to school: The role of self-regulation during early childhood. Sociology of Education, 74 (4), 102-120.

Ministério da Educação (2001). Decreto-Lei no 6/2001 de 18 de Janeiro. Diário da República, $1^{a}$ Série - $A, n^{\circ} 15$. Lisboa.

Ministério da Educação (online). GIASE (Gabinete de Informação e Avaliação do Sistema Educativo) (2006). Séries Cronológicas. Alunos (1985-2005). Lisboa.

Simões, A., Ferreira, J. A., Fonseca, A. C. \& Rebelo, J. A. (1995a). Um estudo dos distúrbios do comportamento e dificuldades de aprendizagem no ensino básico: Opções metodológicas. Revista Portuguesa de Pedagogia, 26 (3), 55-68.

Simões, A., Rebelo, J. A., Ferreira, J. A. \& Fonseca, A. C. (1995b). Prevalência e caracterização das dificuldades de aprendizagem no ensino básico. Revista Portuguesa de Pedagogia, 26 (3), 69-84.

Taborda Simões, M. C., Fonseca, A. C., Formosinho, M. D., Dias, M. L. V., \& Lopes, M. C. (2008). Abandono escolar precoce: Dados de uma investigação empírica. Revista Portuguesa de Pedagogia, 42 (1), 135-151. 


\section{Caractéristiques des élèves redoublants: Une étude dans la région de Coimbra}

Ce travail utilise quelques données d'une étude longitudinale, faite à Coimbra, pour trouver des caracteristiques d'élèves répétents, depuis l'enseignement obligatoire jusqu'au secondaire. Létude a commencé en 1992/93 et il poursuit encore. Dans des diverses occasions, 445 élèves qui, à cette année scolaire, fréquentaient le CE1 et 448 qui, aussi dans la même année, se trouvaient au $\mathrm{CP}_{1}$ ont été évalués. On présente ici une synthèse des résultats obtenus.

La rétention scolaire, dans le système d'enseignement portugais, commence très tôt et la majorité des élèves ne finit pas l'enseignement sans aucune rétention. La majorité des élèves répétents est constituée par des garçons. Dans les premières années scolaires, la rétention semble liée aux difficultés d'apprentissage de la lecture et de l'écriture. De tous les élèves répétents, ceux qui répètent précocement sont les plus défavorisés pendant toute la scolarité, ayant aussi plus qu'une rétention. Le niveau académique de leur parents est plus bas que ce des parents des élèves qui ont réussi toujours, et leur parents semblent moins engagés dans la vie familliale. Il y a beaucoup d' élèves rétenus qui abandonnent l'école sans obtenir un diplôme.

MOTS-CLÉS: rétention scolaire; échec scolaire; élèves répètents; étude de caractérisation.

\section{Characteristics of retained pupils: A study in the region of Coimbra}

The present study uses some data of a longitudinal study, made at county Coimbra, to present some characteristics of grade retained pupils, following them from the primary to the high school. This study started in 1992/93 and is always in follow-up. Since this study year, 445 pupils, who at that time frequented the second class from the elementary school, and 448 pupils who were at that time in the fourth class from the same school level have been assessed some times again. We give a synthesis of the results.

In the Portuguese school system the grade retention begins early and the most students don't finish the high school without they have been retained. The majority of the retained pupils are boys. In the first school years the retention seems to be related with difficulties to learn reading and spelling. Of all the retained pupils, the early retained have the most disadvantages during the school period, especially more than one retention. Their parents have lower scholarship than the parents of the not retained pupils and seem to be more absent of the familiar kernel. Many retained pupils leave the school without diploma.

KEY-WORDS: grade retention; school failure; retaired pupils; study about learners characteristics. 